\title{
A Rare Case of Invasive Keratinizing Squamous Cell Carcinoma of the Foot
}

\author{
Kamal Kant Sahu (iD) \\ Ellen I Roberts ${ }^{2}$ \\ Yayan Chen ${ }^{3}$ \\ Vinod Mohan ${ }^{4}$ \\ 'Department of Internal Medicine, Saint \\ Vincent Hospital, Worcester, MA, 0I608, \\ USA; ${ }^{2}$ Department of Podiatry Medicine, \\ Saint Vincent Hospital, Worcester, MA, \\ 01608, USA; ${ }^{3}$ Department of Pathology, \\ Saint Vincent Hospital, Worcester, MA, \\ 0I608, USA; ${ }^{4}$ Department of Infectious \\ Diseases, Saint Vincent Hospital, \\ Worcester, MA, 01608, USA
}

\begin{abstract}
Lower extremity soft-tissue lesions are frequently encountered in clinical practice. Cellulitis, osteomyelitis, and diabetic foot ulcerations remain the top differentials. The acuity of illness, imaging studies, and deep wound cultures are helpful in most cases. Malignancies are rare but need immediate attention. Hereby, we report a case of a chronic heel wound which on workup was confirmed as cutaneous squamous cell carcinoma (SCC). Keywords: squamous cell carcinoma, malignancy, chronic wound
\end{abstract}

\section{Introduction}

In general, there are three major types of skin cancer: basal cell carcinoma, squamous cell carcinoma, and melanoma. Basal cell carcinoma is the most common primary skin cancer amongst these, and cutaneous squamous cell carcinoma (cSCC) is the second most common skin cancer. Sun-exposed areas are the most common site and mainly affect Caucasians. cSCC involving the lower leg and anogenital region have been more commonly associated with dark skin. ${ }^{1}$ It is of utmost importance to regularly monitor chronic wounds. The conversion from an ulcer to malignancy is usually a slow process and the exact pathogenesis is yet to be definitively known. ${ }^{2}$ It was Marjolin who, in 1827, first reported this process when he noted a malignant change in a chronic ulceration. cSCC is the most common secondary skin cancer noted to arise in chronic wounds, burn scars, trauma, and following radio necrosis. ${ }^{3}$

\section{Case Report \\ Presentation}

A 46-year-old white male who was hypertensive and nondiabetic presented to us with a large left heel fungating mass. The hypergranular mass on his left heel began as a nonhealing chronic wound which had increased in size over the past 4 years. He experienced previous trauma to the area 20 years prior in a car accident, which resulted in a chronic wound that would heal and re-ulcerate over time. The patient denied any recent trauma, insect bite, weight loss, or night sweats. The patient denied any abdominal swelling, limb swelling, or lumps anywhere in the body. The patient did not seek any medical attention for his complaints over the past 4 years.

\section{Examination}

Upon presentation to the hospital, his initial vitals were: Temperature 98.5 degrees Fahrenheit, heart rate 102 beats per minute in normal sinus rhythm, blood pressure 
$131 / 90 \mathrm{mmHg}$, respiratory rate $20 / \mathrm{min}$, and he was saturating $95 \%$ on room air. Musculoskeletal Examination of the patient showed extensive growth to the area of ulceration of the left heel. The mass extended to the midtarsal joint distally, proximally towards the ankle joint, and extending medially and laterally to the malleoli. The wound measured about $15 \times 20 \mathrm{~cm}$. The wound bed was extremely hypergranular (Figure 1A and B), with sparsely fibrotic and necrotic areas. The wound margin was mildly erythematous circumferentially, but intact. No fluctuance or crepitus was noted. The mass was malodorous with mild serosanguinous drainage. Severe pain on palpation and the negative probe to bone was noted. Range of motion to ankle was noted to be severely limited, with the ankle joint in fixed equinus position. Peripheral vascular system examination showed palpable pulses on both lower extremities. The remainder of the physical examination was unremarkable with no organomegaly and lymphadenopathy. Neurological examination showed intact sensory and motor examination with no obvious neurological deficit.

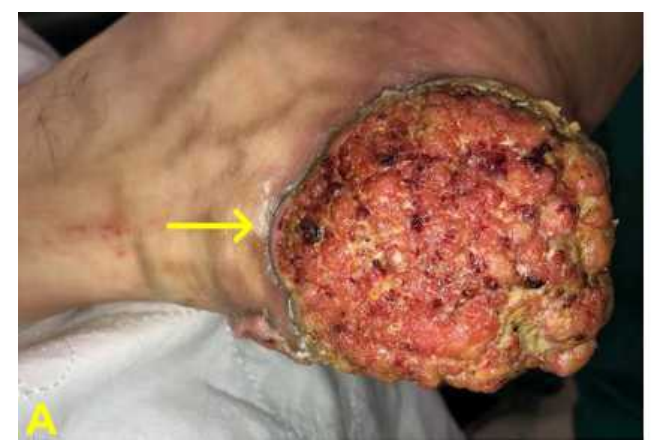

\section{Differential Diagnosis}

Based on the chronicity, local and systemic examination and radiological investigations, the differentials of deep fungal infection, chronic osteomyelitis, and malignancy were considered.

\section{Imaging}

Radiographs reviewed. Left foot x-ray revealed a lytic lesion in the lateral posterior calcaneus (Figure 2). No bone resorption was noted as suggestive of osteomyelitis. CTs o the chest and abdomen were done which did not show any evidence of mass, lymphadenopathy, or organomegaly.

\section{Investigations}

Incisional biopsy of left heel mass was performed under local anesthesia. Final pathology report identified it as invasive keratinizing squamous cell carcinoma, welldifferentiated (Figure 3). Deep fungal/mycobacterial cultures were negative. Laboratory results displayed a total white blood cell count of $4.4 \times 10^{3} / \mu \mathrm{L}$, hemoglobin of 14.0

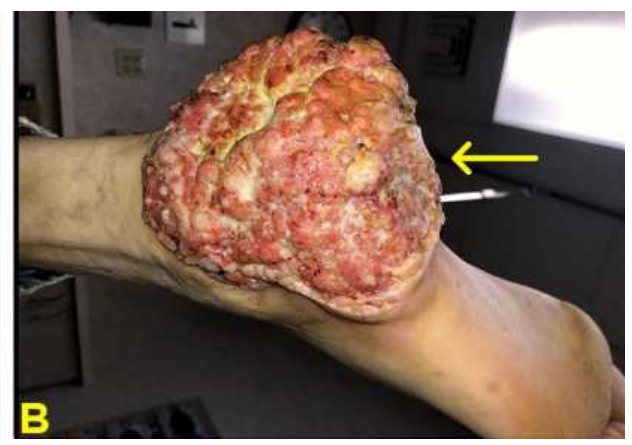

Figure I (A and B) Fungating mass of approximately $15 \times 15 \mathrm{~cm}$ noted at the left heel appreciated via lateral view (A) and inferior view (B).
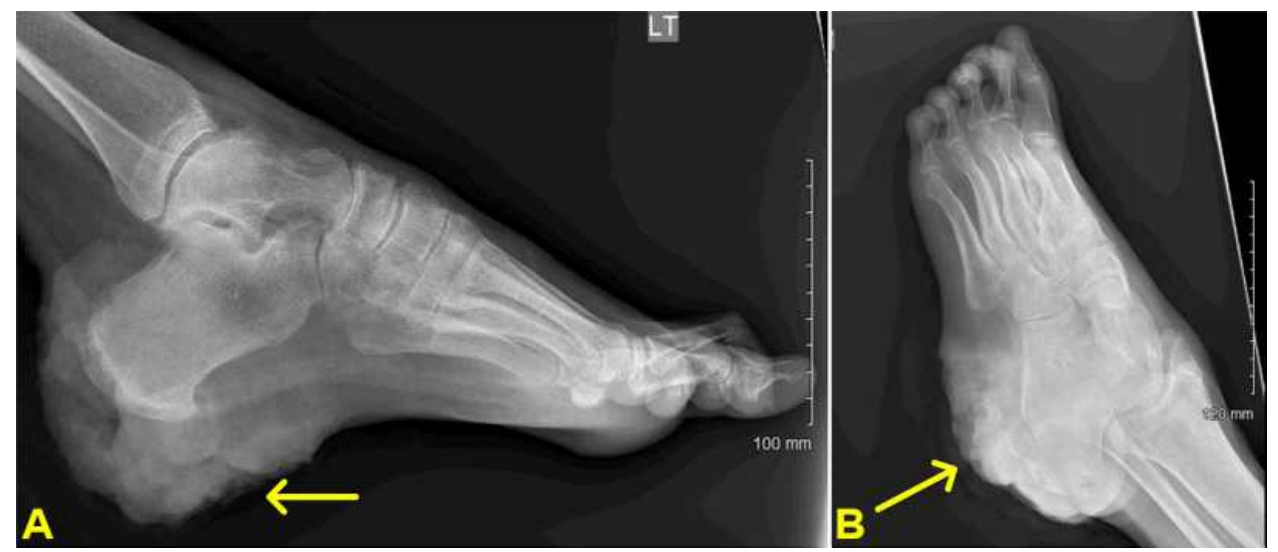

Figure 2 (A and B) Foot X-ray in anteroposterior view (A) and oblique view (B) showing lesion in the lateral posterior calcaneus with surrounding large irregular soft tissue radiopacity/mass. There was no bone resorption that may suggest osteomyelitis. 

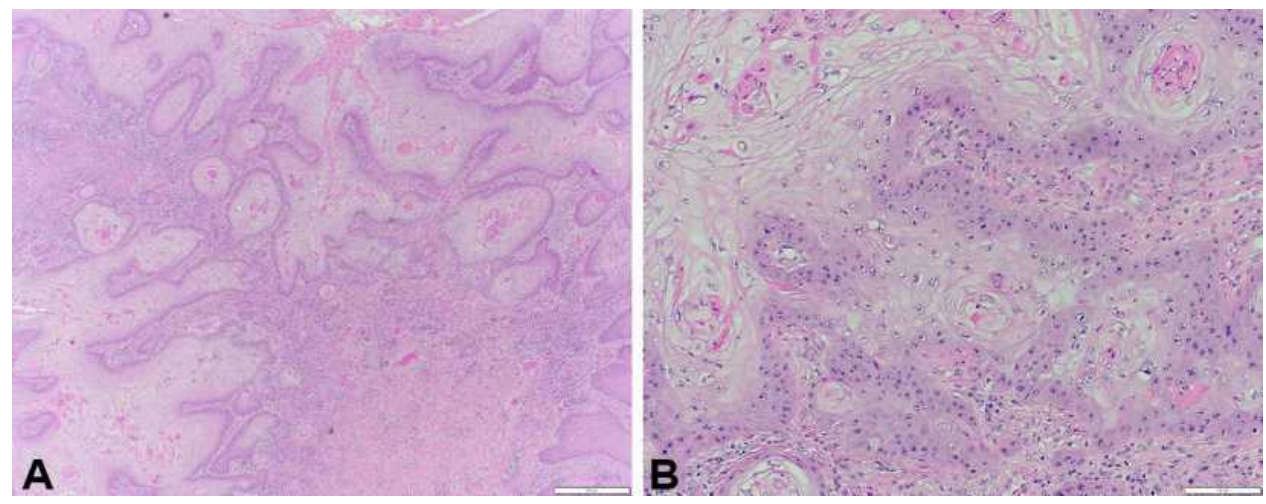

Figure 3 Photomicrograph of histopathologic specimen at low power reveals infiltration of tumor into deep dermis (A) and at high power (B) shows infiltrating islands of well-differentiated neoplasm and squamous epithelium within dermis.

$\mathrm{g} / \mathrm{dL}$, and platelet count of $332 \times 103 / \mu \mathrm{L}$. His ESR was $20 \mathrm{~mm} / \mathrm{h}$ and $\mathrm{HbA} 1 \mathrm{C}$ was 5.7. Liver function and kidney function tests were normal. CTs of the chest, abdomen, and pelvis were also done to rule out metastasis.

\section{Management Plan}

As there was no evidence of metastasis, diagnosis of locally invasive, well-differentiated keratinizing squamous cell carcinoma was made. Oncology referral was placed, and the patient is planned for surgical resection with negative margins versus below-knee amputation. He underwent a left, below the knee, amputation for the invasive, keratinizing, squamous cell carcinoma of skin $(\sim 17.5 \mathrm{~cm})$. On pathological evaluation, the tumor was found to be extending into subcutaneous soft tissue and bone. No lymph vascular or perineural invasion was identified. Bone and soft tissue resection margins were widely free of tumor. The closest soft tissue resection margin noted was $14 \mathrm{~cm}$ from the tumor. The patient is planned for 6 monthly surveillance to rule out recurrence of the disease.

\section{Discussion}

Our case has a few rare findings; the site was the heel, which is uncommon. ${ }^{4}$ Interestingly enough, the foot is usually an uncommon site for cSCC to occur in a white male. cSCC in the lower extremity is common in females and blacks. ${ }^{5}$ Solus et $\mathrm{al}^{5}$ did an institutional review of 61 cSCC cases of the lower extremity and found that $69 \%$ of patients were female and $90 \%$ of the tumors were welldifferentiated. Munday et $\mathrm{al}^{6}$ recently did a retrospective chart review and analyzed the histopathology of SCC of the leg. They found most of the lesions were welldifferentiated and keratoacanthoma like lesions were noted in approximately $40 \%$. It is also very important to timely recognize and differentiate between various close differentials and mimickers. ${ }^{7-10}$ Chronic osteomyelitis is a close mimicker in the case of cSCC and imaging studies and histopathological examination are the essential tools to differentiate the two.

Various factors can predispose to develop SCC. Chronic inflammation, post-traumatic wound, old age, male sex chronic osteomyelitis, and diabetic foot are the major ones which are considered well-established risk factors. ${ }^{11}$ Like our case, Kong et $\mathrm{al}^{12}$ also reported a similar case of left heel cSCC in a 73-year-old with the only major difference of the patient being diabetic. As the lesion was just close to $1 \mathrm{~cm}$, it was completely excised, followed by a split skin graft which subsequently healed completely. In our case, the lesion was quite extensive and would need major surgical excision with long-term wound care, or perhaps a below-knee amputation as the mass had rendered his posterior leg muscles ineffective.

Recently, a retrospective study on invasive cutaneous SCC of the trunk/extremities was done by Mullen et al. ${ }^{13}$ Univariate analysis of 136 patients showed poor differentiation, scar carcinomas, and tumor size $>2 \mathrm{~cm}$ to be significantly associated with death. However, they found that on multivariate analysis only regional nodal disease at presentation was significantly associated with death.

Once the diagnosis of cancer is confirmed, a systematic team approach should be initiated. Cancer staging is the next step and involves a detailed physical examination followed by radiological imaging studies. An examination of the regional lymph nodes, either physically or through the use of ultrasound, is also crucial. Treatment depends on if the tumor can be locally resected with clear margins. Mohs surgery is usually done for larger tumors, for 
cancers which have grown along nerves under the skin, and critical areas like the face or genital area. Radiation therapy is useful in conditions when surgery is technically difficult (eg, eyelid), in cases when the patient refuses surgery, after obtainment of positive surgical margins, and nerve involvement. Advanced SCC would require systemic chemotherapy/immunotherapy.

\section{Conclusion}

It is important to swiftly recognize SCC in a high-risk group and offer the best and most definitive treatment options in a timely fashion. Small and local cSCC can be treated with wide excision only, while advanced cancers require more aggressive treatment. It is important to closely follow and evaluate any chronic non-healing ulcer as there is always a possibility to harbor malignancy that may go unnoticed for a long time if not addressed properly and in a timely fashion.

\section{Ethical Statement}

The article doesn't contain the participation of any human being or animal.

\section{Informed Consent/Institutional Approval}

Informed consent was obtained from the patient to publish their case details and accompanying images. This case report did not require any institutional approval as per the IRB guidelines of our hospital.

\section{Author Contributions}

All authors contributed to the data analysis, drafting or revising the article, have agreed on the journal to which the article will be submitted, gave final approval of the version to be published, and agree to be accountable for all aspects of the work.

\section{Disclosure}

The authors have no conflicts of interest to declare.

\section{References}

1. Gupta AK, Bharadwaj M, Mehrotra R. Skin cancer concerns in people of color: risk factors and prevention. Asian Pac J Cancer Prev APJCP. 2016;17(12):5257-5264. doi:10.22034/APJCP.2016. 17.12.5257

2. Henning J, Rasor Z, Brown A, Blanchard A, Hall B. Primary Invasive Squamous Cell Carcinoma of the Foot. $J$ Am Podiatr Med Assoc. 2020;110(4). doi:10.7547/18-053

3. Ackroyd JS, Young AE. Leg ulcers that do not heal. Br Med J Clin Res Ed. 1983;286(6360):207-208. doi:10.1136/bmj.286.6360.207

4. Mansour O, Moussa MK, Raad RB, Zreik H, Allouch AH. Squamous cell carcinoma of the heel invading the calcaneus treated by radical excision and reverse sural flap. Cureus. 2020.

5. Solus JF, Murphy GF, Kraft S. Cutaneous squamous cell carcinomas of the lower extremities show distinct clinical and pathologic features. Int $J$ Surg Pathol. 2016;24(1):29-36. doi:10.1177/ 1066896915599058

6. Munday WR, Leffell DJ, McNiff JM, Ko CJ. Histopathologic features of multiple cutaneous squamous cell carcinomas of the lower extremity. $J$ Cutan Pathol. 2016;43(9):759-765. doi:10.1111/ cup. 12738

7. Sahu KK, Mishra AK, Martin K, Chastain I. COVID-19 and clinical mimics. Correct diagnosis is the key to appropriate therapy. Monaldi Arch Chest Dis Arch Monaldi Mal Torace. 2020;90(2).

8. Sahu KK, Sawatkar GU, Sahu SA, Mishra AK, Lal A. PentazocineInduced Skin Ulcers. Am J Med Sci. 2020;359(3):182-183. doi:10.1016/j.amjms.2019.09.001

9. Lefkovits Y, Adler A. Fatal squamous cell carcinoma from necrobiosis lipoidica diabeticorum in a diabetic patient. Endocrinol Diabetes Metab Case Rep. 2019;2019. doi:10.1530/EDM-19-0007

10. Clutter CA, Aneja S, Ivan D, Ciurea A, Silapunt S. Cutaneous lesions of multiple myeloma of the lower extremity masquerading as squamous cell carcinoma. Cureus. 2020;12(11):e11313. doi:10.7759/ cureus. 11313

11. Dörr S, Lucke-Paulig L, Vollmer C, Lobmann R. Malignant transformation in diabetic foot ulcers-case reports and review of the literature. Geriatr Basel Switz. 2019;4(4).

12. Kong M-F, Jogia R, Nayyar V, Berrington R, Jackson S. Squamous cell carcinoma in a heel ulcer in a patient with diabetes. Diabetes Care. 2008;31(7):e57. doi:10.2337/dc08-0284

13. Mullen JT, Feng L, Xing Y, et al. Invasive squamous cell carcinoma of the skin: defining a high-risk group. Ann Surg Oncol. 2006;13 (7):902-909. doi:10.1245/ASO.2006.07.022

\section{Publish your work in this journal}

The International Medical Case Reports Journal is an international, peer-reviewed open-access journal publishing original case reports from all medical specialties. Previously unpublished medical posters are also accepted relating to any area of clinical or preclinical science. Submissions should not normally exceed 2,000 words or 4 published pages including figures, diagrams and references. The manuscript management system is completely online and includes a very quick and fair peer-review system, which is all easy to use. Visit http://www.dovepress.com/testimonials.php to read real quotes from published authors. 